\title{
Tourist Pathways in Cities: Providing insights into tourists spatial behaviour
}

\author{
DEBORAH EDWARDS \\ University of Technology, Sydney \\ Management Group, UTS Business School \\ PO Box 222 \\ Lindfield NSW 2070 \\ Australia \\ Tel: +61-2-9514-5424 \\ Fax: +61-2-9514-5195 \\ E-mail: Deborah.edwards-1@uts.edu.au \\ TONY GRIFFIN \\ University of Technology, Sydney \\ Management Group, UTS Business School
}

\begin{abstract}
Edwards, Deborah and Griffin, Tony, Tourist Pathways in Cities: Providing Insights into Tourists Spatial Behaviour (November 2011). Available at SSRN: http://ssrn.com/abstract=2042291
\end{abstract}

\begin{abstract}
Cities are shaped by flows of people, money and goods. Amongst the people who move through cities are tourists. The types of activities and spaces within cities that satisfy a tourist's needs are often concentrated into distinctive geographic areas - precincts - and the tourist's experience is most commonly one of moving between these precincts in search of the city's highlights. While the movement of tourists through cities is observable, it is complex and not well understood. Understanding tourists' spatial behaviour can greatly assist those engaged in the management and planning of urban destinations. To address this issue, since 2007 researchers in the Urban Tourism Program at the University of Technology Sydney have been examining tourists' spatial behaviour using GPS technology, in tandem with other methods that assist with 'interpreting' the spatial activity. Studies have been conducted in Sydney, Canberra, London and Melbourne. This paper provides insights into how tourists view and use the city, highlighting differences in their general patterns and range of movement in these cities.
\end{abstract}

\section{Introduction}

Understanding the places tourists visit, the time they spend and the services they utilise while in a destination can provide valuable information for many engaged in the management or study of tourism. This information can be used for such purposes as informing location choices for restaurants, accommodation or attractions in order to maximise exposure to visitor traffic. Government agencies and destination managers can use the information to inform land use planning decisions, manage visitor flows to avoid overcrowding, minimise 
adverse impacts on sensitive sites, concentrate marketing activities, inform transport policies and more broadly distribute expected benefits. In major cities, in particular, it can be challenging to acquire this information because of their complexity and the diversity of experiences they offer tourists. It can also be difficult to discern the presence of tourists in certain parts of the city, as they may blend in with residents engaged in their normal daily activities. Even in urban tourism precincts the majority of people present at any one time may well be locals at leisure rather than tourists. The purpose of this paper is to demonstrate how emerging tracking technologies can be employed to provide a better understanding of tourists' spatial movements in cities. It reports on studies conducted in three Australian cities, Sydney, Canberra and Melbourne, and London, UK between 2007 and 2010. The paper firstly presents a brief overview of the state of knowledge about tourists' spatial behavior in cities and previous applications of Global Positioning System (GPS) technology in that context.

\section{The Spatial Behaviour of Tourists in Cities}

Generally, the spatial behaviour of tourists in cities is not well understood. Partly, this is because few studies have sought to specifically explore and anlyse the behaviour of tourists in cities. In a critique of textual and representational studies Selby, Hayllar and Griffin (2008) note the tendency for such studies to read landscapes on behalf of people, rather than seeking to understand how they experience such places. They argue that a better understanding is needed of the tourists' perspectives and of the ways in which they visit places, such as their spatial movements, the time they spend and the services they utilize.

Urban destinations are indeed challenging environments in which to analyse and understand tourist experiences and behaviour. Urban is both virtual, in its notion of an urban sensibility, and real, as people negotiate their way through the internal and external structures that typify the urban fabric (Edwards, Griffin and Hayllar, 2008). A city, moreover, has a multiplicity of users - office workers, residents, recreational visitors and tourists - who each use its spaces and places in different ways. Rarely are urban spaces and places devoted entirely to tourist uses. Increasingly it has also been recognised that tourists wish to explore the everyday aspects of the cities they visit (Maitland, 2008), but the extent and nature and their wanderings and exploration are difficult to both detect and predict in the complex and crowded urban milieu.

Space can be understood in different ways. In evaluating tourist flows Mansfeld (1990) suggests that tourism space can be viewed as: the actual space which denotes the area that accommodates tourism activities and has clear geographical boundaries; functional space which views tourism space as including both generating and attracting areas; and perceived space which refers to the personal perceived images of space that tourists have on an individual level. However generating and attracting areas are not discrete spaces but are open and at the centre of social processes for those who live in the space and those who visit; constantly being created, abandoned and re-created (Shaw and Williams, 2004).

Lew and McKercher (2004) suggest that tourist spatial patterns can be classified into four broad themes: single destination with or without side trips; transit leg and circle tour; circle tour with or without multiple access points; and a hub and spoke style. However, McKercher and Lau (2008, p.357) further argue that mapping tourist movements is "complicated by the virtually unlimited number of places that tourists could visit, an 
unpredictable sequencing order between places, the potential for stochastic movement patterns that may follow no logical pattern, and the unique needs and wants of individual tourists".

Spatial analysis involves looking at geographic patterns in spatial data and relationships between features. Spatial analysis of tourist behaviour seeks to bring some order and understanding to tourists' negotiation of the urban environment. Traditionally the spatial behaviour of people has been measured using labour-intensive methods such as surveys, traffic and people counts, travel or trip diaries, and observation. These methods have often led to unrealistic or overly simplistic models and theories with respect to behavioural complexities and the complexity of real urban environments (Kwan, 2000) and they are challenging in that they have limited spatial and temporal precision due to recall bias and limits to people's knowledge of the area being studied (Duncan et al, 2007). Spek (2008) also states that people's ability to reproduce a walking route on a map is inadequate. Finally, spatial frameworks using these methods do not lend themselves to analysis at the individual level and typically do not incorporate accurate data about the individual's behavioural patterns.

The shortcomings discussed above are being overcome with new technologies and analytical tools (Barker, 2006). In recent years, the rapid development and availability of small, cheap and reliable tracking devices drawing on GPS technology have led to new methods of spatial research. GPS offers several advantages over traditional methods, as it allows the precise and continuous tracking of individuals and provides spatially rich data including velocity and timing information (O'Connor, Zerger, \& Itami, 2005) making it possible to accurately track the paths tourists are taking and to provide greater understanding of their socio-spatial behaviour (Asakura and Iryo, 2007). For these reasons there has been a flurry of simultaneous activity over the past few years in studies that examine tourists' spatial movements.

Arrowsmith and Chhetri (2003) undertook a pilot study using handheld GPS receivers to monitor the movement patterns of tourists through a national park in southwest Victoria, Australia. D'Antonio et al (2010) also examined patterns of visitor use and intensity in national parks utilising GPS tracking methods. Compared to observational data and survey techniques, GPS-based methodologies require minimal time demands on the visitor and less training of staff for data collection (D'Antonio etal, 2010).

ten Hagen, Kramer, Modsching and Gretzel (2006) captured the spatial behaviour of tourists in the inner city of Görlitz, Germany. Kempermann, Chang-Hyeon and Timmermans (2004) recorded significant differences between first time visitors and repeat visitors to a theme park. It was found that new visitors try to get to as many attractions as possible, whereas repeat visitors were more selective and focused. Shoval and Isaacson (2007) used both conventional and new methods to collect data on the spatial and temporal activities of tourists. The focus of this study was to consider "whether and to what extent the various new digital tracking technologies can help further research into the spatial and temporal behaviour of tourists" (Shoval and Isaacson, 2007, p.143). Spek (2008) carried out a series of pedestrian tracking studies on a range of tourist types in three European cities: Norwich (United Kingdom), Rouen (France) and Koblenz (Germany). He concluded that the study provided good insights into the behaviour of various types of visitors such as walking distance, duration, familiarity and that visitors to each city behaved in different ways. 
Generally, the method of GPS tracking has demonstrated its vast potential to provide a better understanding of tourists' spatial behaviour. As the series of studies reported below also demonstrates, it also has immense potential for use as a diagnostic device for managers of urban tourist destinations.

\section{Research Method}

Three tracking studies, using similar methods, were conducted in four capital cities to better understand the spatial movements of tourists in urban environments. The first study was conducted in Sydney and Canberra between 2007 and 2008. The second was conducted in London over one week in June 2009. The third was conducted in Melbourne over two weeks in May, 2010.

The overall intent of these studies was to build a picture of the spatial patterns of tourists how they navigate the urban environment and the routes they take. To build a more complete picture, the GPS tracking was complemented by post visit interviews and participant questionnaires. The interviews allowed participants to explain their routes and various spatial decisions taken during the course of the day. For the purpose of these studies, a tourist was defined as a visitor to the city, from outside their usual home and work environment and staying at least one night. Participants included both domestic and international tourists.

\section{Tracking Tools}

This study employed three different GPS tracking devices; GPSports SPI Elite, Garmin Forerunner 305 and Holux Loggers. All devices record time, speed, distance, position, altitude and direction. The GPSports SPI Elite, is cigarette lighter in size and could sit in a pocket or bag while the Garmin is a watch-style device worn on the wrist. The Holux Logger resembled a roll of camera film and was worn around the neck. The Garmin 305 and Holux Logger were compatible with a free downloadable program, "SportTracks", which incorporated a number of features that were helpful for data collection and storage. GPSports SPI Elite, came with its own program. In a small trial of all devices it was found that they all collected comparable data, however the GPSports SPI Elite was found to be not as reliable as the other devices and was therefore not used after the first study.

\section{Participant Recruitment and Venues}

Participants were recruited from accommodation venues in each city. Venue choice was moderated by its geographic dispersal in the city and ability to offer distinct starting points for tourists' engagement with the city. The selection of venues was also largely dictated by the willingness of accommodation managers to permit the researchers to recruit participants on their premises. While considerable time was devoted to attempts at obtaining permission from a range of accommodation types and locations within each city, managers of accommodation establishments above a budget level were generally not willing to allow their premises to be used for the project. Other considerations included a high occupancy rate at the time of the project (to ensure a sizable pool of potential participants), appropriate spaces in which to both recruit and interview participants (privacy, adequate seating and space for equipment) and technical requirements such as access to wireless internet.

\section{Administration}


Information letters were distributed in venues in the evening prior to the day of data collection. Guests were advised of the project, its objectives and their requirements, and the availability of an incentive (a shopping voucher) for participation. Active recruitment was then undertaken the following morning. They were asked to wear or carry a GPS device that would record their location, time, speed, distance and direction over the course of a day. The devices were set by the research team before the participants departed and they were advised to go about their day as they normally would and to "forget" they were carrying the device.

Upon returning to their accommodation at the end of the day a debriefing was conducted with each participant in conjunction with a semi-structured interview. As part of this process they completed a questionnaire which was designed to capture demographic information along with their purpose for visiting, the activities they engaged in, modes of transport used and any barriers they may have encountered. During the debriefing process data collected from the GPS devices were downloaded into the Sportracks program. From here the data were exported into Google Earth and overlayed onto a map of the location, thus providing an immediate representation of the participant's trail. The trail was reviewed with the participant and notes were taken of any wayfinding difficulties, the participant's reasons for choosing sites and their activities of interest. A total of 40 participant groups were recruited in each location with the exception of Melbourne which captured 117 groups.

More participant groups were captured in Melbourne because the supporting organisation requested three stages be conducted in this study. Stage one used the same method as Sydney, Canberra and London. In stage two, the researchers were directed to instruct participants to visit one of the City of Melbourne's visitor information centres before going about their day. In stage three, participants were delegates who were taking time out from attending a conference in the destination.

\section{Analysis}

The software supporting the GPS devices enabled the overlaying of trails onto Google Earth. The technology provided clear evidence of the path taken, speed travelled and time of day. Trails were examined individually and then collectively on one map, showing both individual trails and the intensity of activity along particular paths.

\section{Findings and Discussion}

The spatial patterns in each city highlight areas of substantial intense use while contiguous areas of potential interest remained 'underutilised', and the significance of iconic attractions and places as shapers of spatial activity are highlighted. Tourist's spatial patterns were not representative of any particular theme as identified by Lew and McKercher (2004). Common to the Sydney, Melbourne and London studies is the preparedness of tourists to walk between 10 and 35 kilometres a day. Walking the city affords tourists the opportunity to become connected. According to Montgomery (2006), connectedness is achieved in cities that allow maximum scope for activity for people of all ages and backgrounds, is organised so that its form and functions are easily understood and provides access to resources, services and information when needed. However there were also some significant differences in the general patterns and range of movement, the modes of transport used and the ease with which tourists felt they could find their way around the various cities. The key findings from each city are reported separately below, with some common issues identified at the end of this section. 
Sydney

Tourists' spatial behaviour in Sydney is based on the city core or 'spine' (Image 1).

Participant's trails suggest that Sydney has a spatial order which is referred to as successive arrangement: a spatial system that generates fragmented integration with disjointed parts and limited choices for experiencing space, resulting in people becoming stuck in a core and finding it difficult to penetrate all parts of the system (Boerwinkel, 1995). Navigating their way through Sydney, participants found elements such as signage, the challenges of public transport and ticketing created difficulties for wayfinding including the location of key cultural attractions. This type of spatial system tends to facilitate repetitive movements. Once tourists found a path from A to B they tended to retrace their steps or use the same path on future trips. The Sydney trails indicate a high degree of repetitiveness with participants returning to the same places and using the same routes. Transport and wayfinding in Sydney were at times compared unfavourably to European cities.

Image 1. Sydney Trails

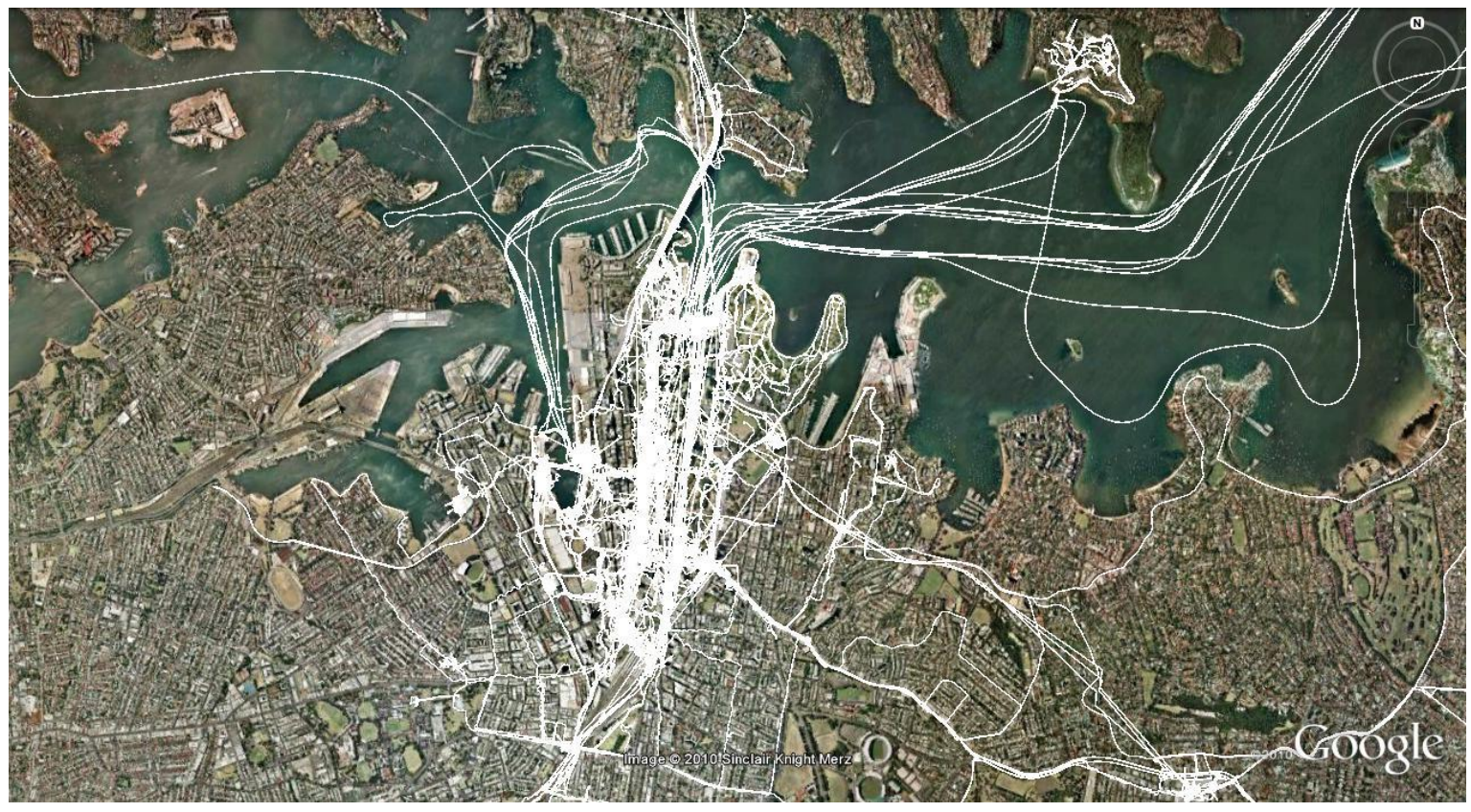

\section{Canberra}

Being the national capital, the geographic focus of many visits in Canberra is the Parliamentary Zone on the southern shores of Lake Burley Griffin (Image 2). No tourists circumnavigated the lake. In spite of numerous attractive cycle ways around the whole lake area, tourists only used these paths to access sites such as the Canberra Visitors Centre and the National Museum of Australia.

Tourist spatial behaviour in Canberra indicates that there is a clear emphasis on the use of private vehicles and a disinclination to experience Canberra by bicycle or foot. Canberra has a number of cycle paths around the city and between major attractions, however few tourists used these paths for either cycling or walking. This is unfortunate as there is 
consequently little opportunity for tourists to understand the city's form and function and to connect with Canberra beyond its 'seat of government' image.

Image 2. Canberra Trails

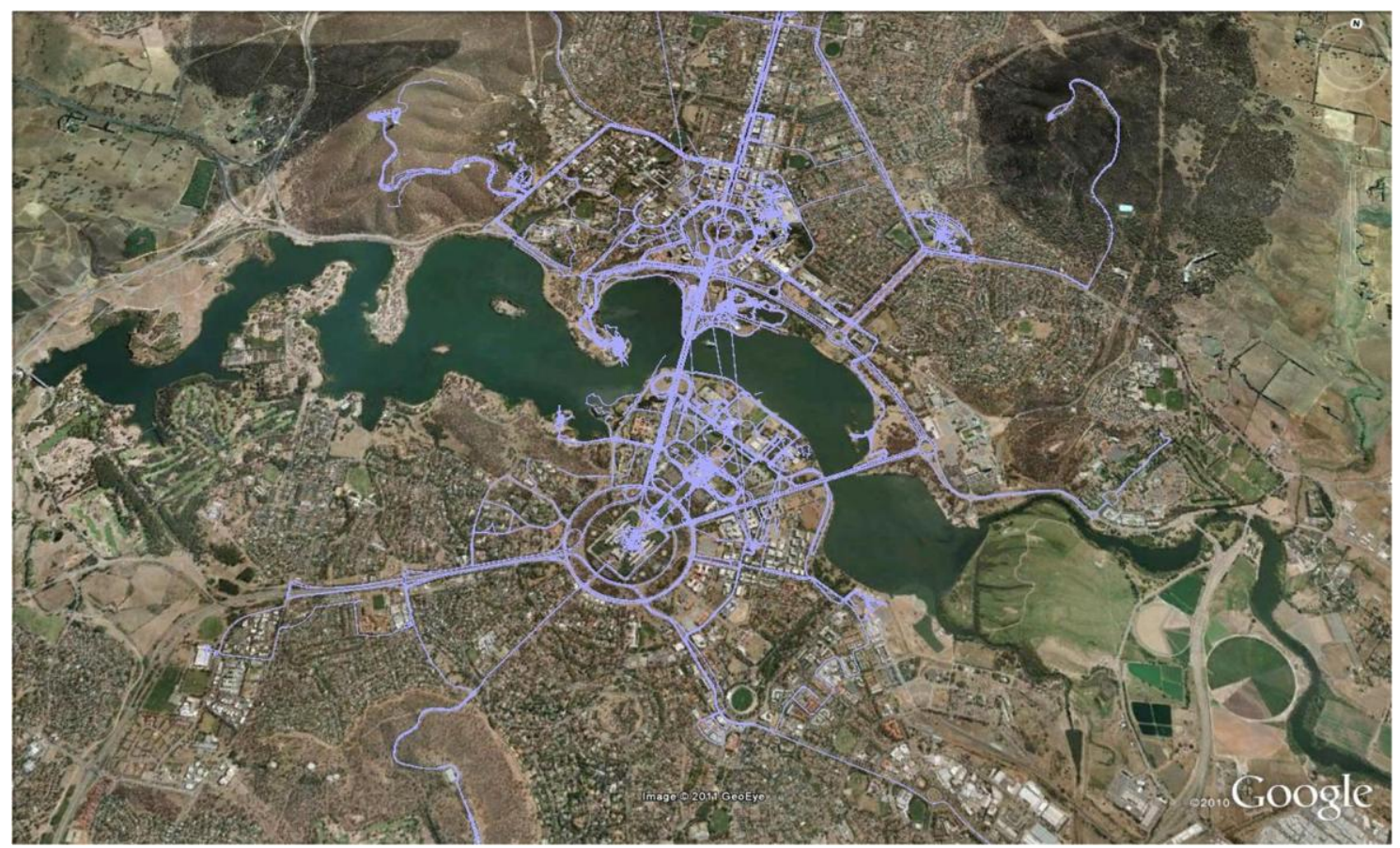

There may be a number of reasons why tourists prefer vehicular transport to move around Canberra even though the city's spatial design and infrastructure are supportive of walking. They may perceive the attractions as being too far apart to navigate 'by foot', with little to stimulate their interest in between. Time pressure may also be a factor as participants frequently commented that a couple of days 'wasn't enough' to see all the attractions. The length of stay at major attractions, which may be up to four hours (Ritchie \& Dickson 2007), may impact upon visitors' willingness to add further effort to their day by walking back to their hotel or to the next attraction. Finally, because tourists try to see all the major attractions during their visit they may feel an urgency to move between attractions as quickly as possible.

\section{London}

In a number of ways the outcomes from London mirrored the findings from both Sydney and Canberra. Major tourist attractions and available transport help shape the tourist experience. In London, tourists tended to travel in an anti-clockwise direction with their initial focus on the iconic inner city sights such as Trafalgar Square and then moving toward the Thames and Houses of Parliament (Image 3). Along the way many deviated to the Strand, The Mall and Buckingham Palace. The south side of the Thames seemed to provide some form of respite and also the opportunity to explore areas of the city that were somewhat off the beaten track.

While much of the above was theoretically predictable, the trails also revealed some interesting aspects of tourists' behaviour. For example, while a visit to the National Gallery adjacent to Trafalgar Square was reasonably common, timing on one GPS trail revealed that a 
visitor had spent only 10 minutes in the gallery. When questioned, the participant replied that they only wanted to view Van Gogh's Sunflowers and nothing else. A further group of visitors spent their first day at the movies, while another had caught a bus to an outer suburb of London to purchase inexpensive clothes at a major shopping mall.

Like visitors to Sydney in particular, the majority of visitors spent a considerable amount of their time just walking and exploring. In a culturally rich city such as London, the engagement with many of the iconic and somewhat lesser known sights of London, such as the Baker Street of Sherlock Holmes, was as much serendipity as it was planning. Tourists' spatial behaviour around London represents 'simultaneous' arrangement (Boerwinkel, 1995). This arrangement is facilitated by London's variously located major attractions which act as anchor points, drawing tourists to different parts of the city.

Image 3. London Trails

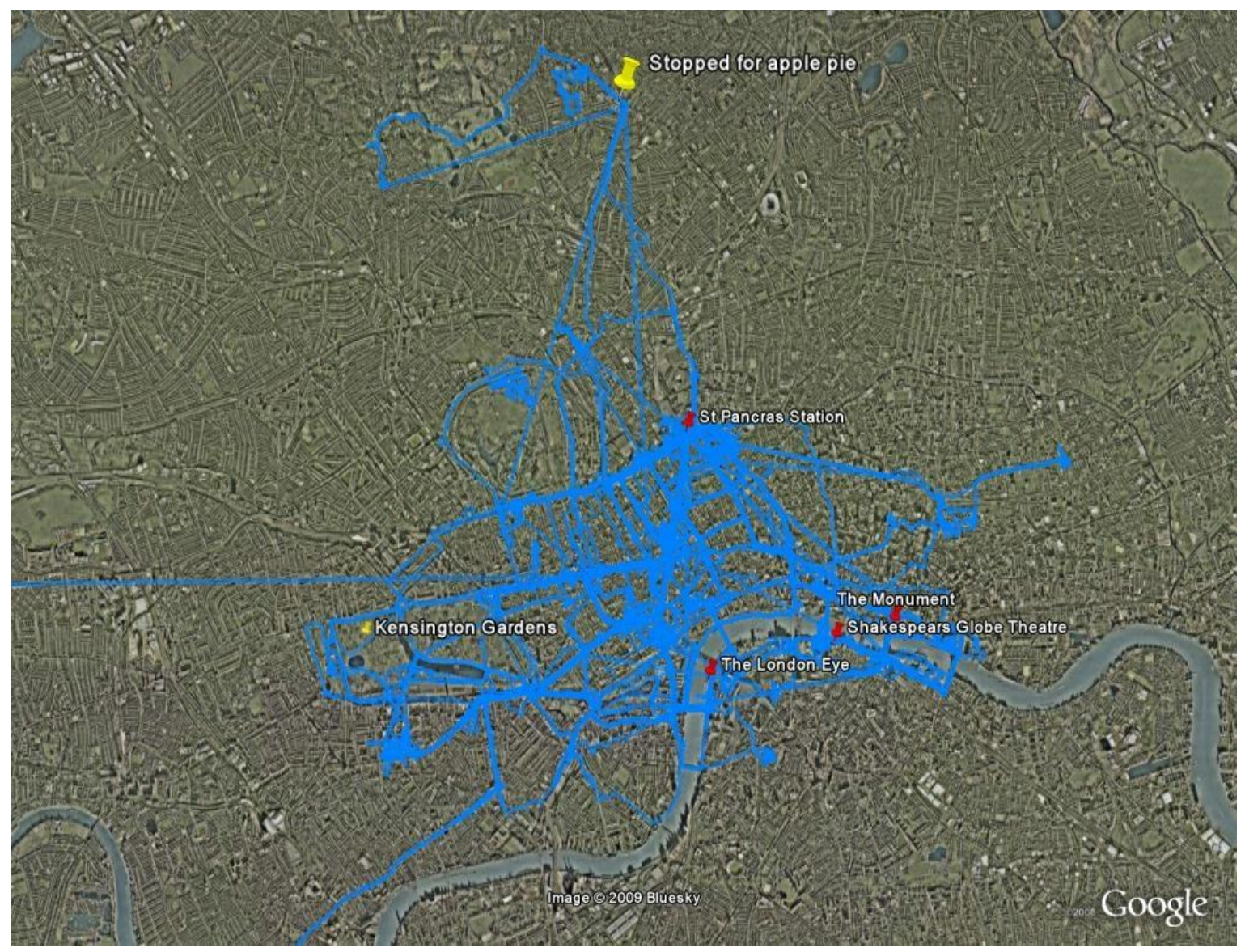

\section{Melbourne}

In Melbourne activity was particularly focused on the CBD (Image 4). Participants clearly felt comfortable moving about and exploring the city centre fairly thoroughly. For the central area at least, Melbourne emerged as an easy city for the visitor to explore, offering rewarding experiences en route as well as at focal attractions. The free City Circle Tram (CCT) was very popular with participants, who used it as a means of orientating themselves to the city.

Melbourne's laneways CCT and free tourist shuttle bus appear to offer the tourist an integrated system for making their way around the city. The city offers diversity of 
experiences, sights, attractions and activities and this integrated system enables tourists to cover all the different parts. The city has a focus on creative art and enlivening small places (micro spaces) which may be facilitating 'by-chance-encounters' for tourists enabling them to make their way from one space to another within the system. Overall, tourists' dominant patterns of use in Melbourne also represent simultaneous arrangement.

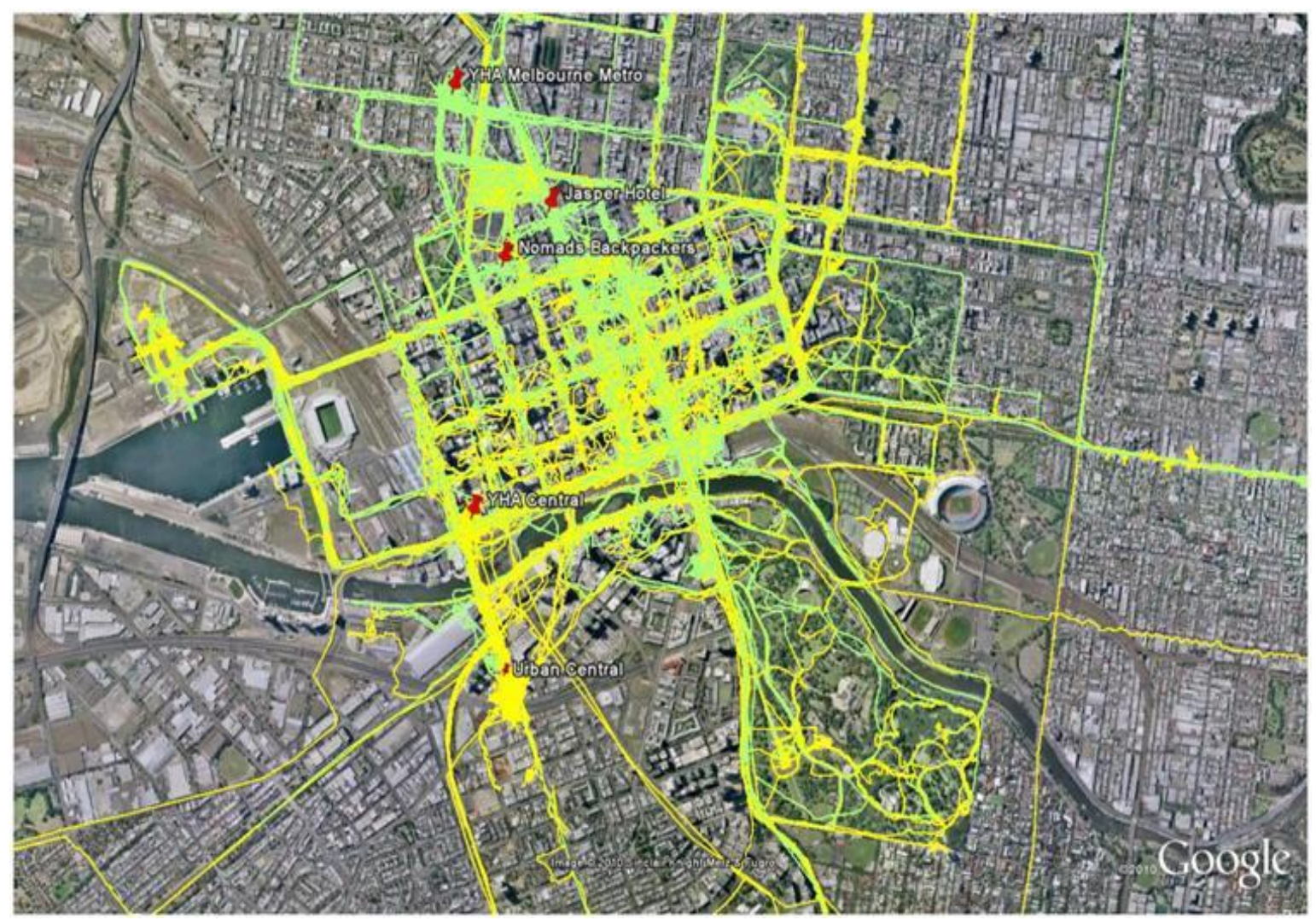

*Stage 1 - yellow; Stage 2 - green

A visit to one of the City of Melbourne's visitor information centres (VICs) resulted in a slightly stronger concentration of more linear movements: up and down two main streets of Melbourne - Swanston and Elizabeth Streets. The patterns do not fully reflect the impact of the VICs as participants had planned their activities prior to setting out. However, participants stated that they intended to undertake some of the activities recommended by the volunteers and staff from the VICs on subsequent days. Given the city-centric activities recommended to the study participants it could be assumed that the dense spatial patterns exhibited by visitors in stage 1 would be largely repeated. 


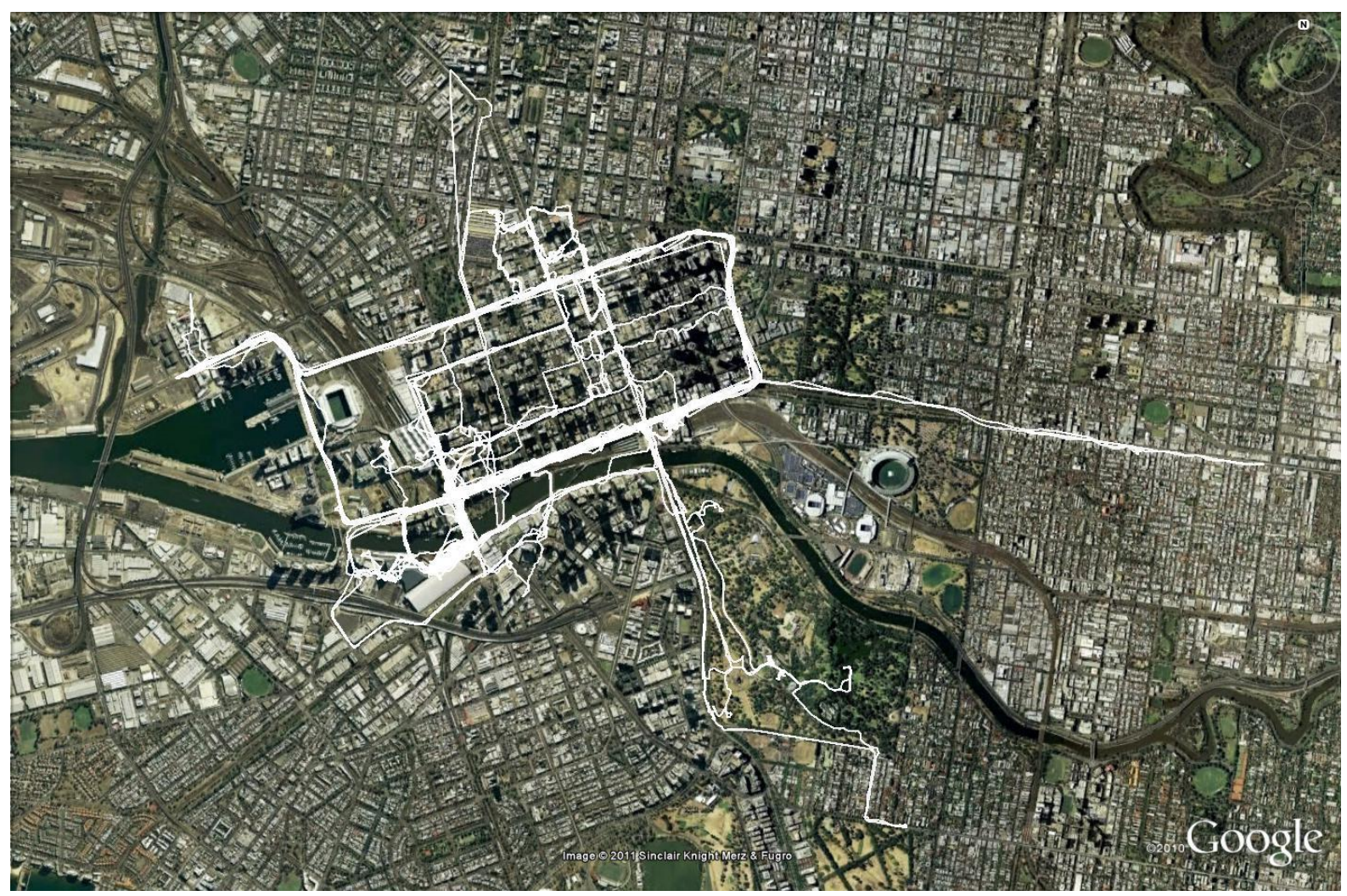

The third stage of the Melbourne study focused on conference delegates taking time out. "Time out" is seen by conference delegates as an opportunity to gain some relief from a heavy conference schedule, see some of the city, meet with friends and colleagues, and to go shopping. In general the CCT has a big influence on the movement patterns of conference delegates along Flinders, Spring and La Trobe Streets and to Docklands (Image 5). Time is clearly at a premium for this group of visitors and the CCT facilitates quick and easy exploration of the city centre. Southbank along with Collins and Lonsdale Streets to the west of Swanston Street was also fairly heavily used. It became apparent that there was an opportunity to develop themed trips of only a couple of hours' duration to assist delegates to maximise the short time they have available and increase occasions for expenditure.

\section{Common Issues}

Common issues of concern raised by tourists across all studies focused on transport, maps, signage and information regarding attractions and general services. An efficient transport system enables people to get from A to B, however as visitors will walk up to 35 kilometres a day they can be more interested in exploring the fine grain of the city and finding "somewhere else" to go. This 'somewhere else' can be a deeper exploration of the city core or other places of interest within the wider urban area. Amongst the key constraints that visitors reported as limiting the range of their exploration of a city was their knowledge of the public transport network and ticketing system and the quality of a city's wayfinding system. 
An effective wayfinding system allows people to: determine their location within a setting; determine their destination; develop a plan to take them from their location to their destination, including identifying places of interest en route; and reduce frustration and wasted time. Successful wayfinding systems lead to more satisfactory experiences for visitors. From a public policy perspective, effective wayfinding systems can also help spread visitor expenditure more broadly throughout the city. Wayfinding is more than generating a pictorial map of a spatial situation; it is decision-based behavior (turn right, go up, look for information) in response to an environment (buildings, streets, intersections, stairs, billboards, shops, lighting). Wayfinding is a dynamic cognitive process where movement through spaces requires continuous involvement in reading, interpreting and representing that space. It involves a variety of search processes and sources of information. In this respect emergent technologies present new opportunities for agencies to explore innovative wayfinding methods that move away from pictorial maps and static signage to multiple options and direct user interface.

\section{Conclusion}

As an emerging application of available technologies in a tourism context, the knowledge generated from this study provides a basis for the future development of alternative, reliable and cost-effective methods for gathering data on the spatial behaviour of urban tourists, as well as a comparison with other data collection methodologies such as travel diaries. The accuracy and detail of information about trails and the time spent in different attractions far exceeds anything that can be gathered through travel diaries or post-travel surveys. Though using such modern equipment provides a clear view, it does not negate the need to collect supporting information and feedback via other methods to help interpret the trails. We would argue in fact that in the context of this study it was critical to use GPS technology in tandem with other methods to assist with interpreting the spatial activity. These methods include debriefing interviews and questionnaires.

Whilst the spatial data provides insights to patterns of use it is important not to neglect the tourists individual issues and serendipitous actions. The debriefing interview gave us additional information on how people orientated themselves and their barriers to movement, which provided insights into issues such as the adequacy of directional signage and tourist information. These methods help capture the richness of the individual tourist experience.

The information has diagnostic value in that it can inform destination managers in relation to evaluating the adequacy of current services and facilities, such as signage, transport and visitor information services. More broadly, it can reveal how visitors form itineraries and how they use and experience the city. This contributes to a better understanding of the city's appeal to visitors and how effectively it is functioning as a tourist destination. It can further suggest ways of enhancing that experience by enabling tourists to more thoroughly explore a city by reducing barriers to movement. 


\section{Acknowledgments}

The Sydney and Canberra studies were supported by the Sustainable Tourism Cooperative Research Centre and Destination New South Wales. The Melbourne study was supported by the City of Melbourne.

\section{References}

Asakura, Y., Iryo, T. (2007) Analysis of Tourist Behaviour Based on the Tracking Data Collected Using Mobile Communication Instrument. Transport. Res. Part A 41(7):684690.

Arrowsmith, C., \& Chhetri, P. (2003) Port Campbell National Park: Patterns of Use. Melbourne, Victoria: Department of Geospatial Science, RMIT University.

Barker, M. (2006) A Suvey on Agent-Based Modelling of Pedestrian Movement, University of Central Florida, USA.

D’Antonio, A., Monz, C., Lawson, S., Newman, P., Pettebone, D. \& Courtemanch, A. (2010) GPS-based Measurements of Back Country Visitors in Parks and Protected Areas: Examples of Methods and Applications from Three Case Studies, Journal of Park \& Recreation Administration, 28(3), 42-60.

Boerwinkel, H. W. J. (1995) Management of recreation and tourist behaviour at different spatial levels, in G. J. Ashworth \& A. G. J. Dietvorst (Eds.) Tourism and Spatial Transformations-Implications for Policy and Planning. pp. 241-263. Wallingford, UK: CAB International.

Duncan, M., Mumery, K. \& Dascombe, B.J. (2007) Utility of Global Positioning System to Measure Active Transport in Urban Areas, Medicine and Science in Sports and Exercise, Vol. 39, No. 10, pp. 1851-1857.

Edwards, D., Griffin, T. \& Hayllar, B. (2008) Urban Tourism Precincts: An Overview of Key Themes and Issues. In B. Hayllar, T. Griffin, and D. Edwards (Eds.) City Spaces - Tourist Places: Urban Tourism Precincts. UK: Elsevier.

Kwan, M. (2000) Analysis of Human Spacial Behaviour in a GIS Environment: Recent Developments and Future Prospects. Journal of Geographical Systems, 2(1), 85-90.

Lew, A. \& McKercher, B. (2006) Modeling Tourist Movements: A Local Destination Analysis. Annals of Tourism Research, Vol. 33, No. 2, pp. 403-423.

O'Connor, A., Zerger, A. \& Itami, B. (2005) Geo-Temporal Tracking and Analysis of Tourist Movement. Mathematics and Computers in Simulation, vol. 69, pp. 135-150.

McKercher, B. \& Lau, G. (2008) Movement Patterns of Tourists within a Destination. Tourism Geographies, 10(3), 355-374

Maitland, R. (2008) Conviviality and everyday life: the appeal of new areas of London for visitors. International Journal of Tourism Research, 10(1), 15-25.

Ritchie, B. W. \& Dickson, T. J. (2007) ACT attractions: Direct Visitor Expenditure and Visitation Patterns Study. Report prepared for the Sustainable Tourism Cooperative, Research Centre. Gold Coast.

Selby, M., Hayllar, B. R. \& Griffin, A. R. (2008) The Tourist Experience of Precincts, In B. Hayllar, T. Griffin, and D. Edwards (Eds.), City Spaces - Tourist Places: Urban Tourism Precincts, pp. 183-202. Oxford: Butterworth-Heinemann.

Shaw, G. \& Williams, A.M. (2004) Tourism and Tourism Spaces. London, GBR: Sage Publications.

Shoval, N. \& Isaacson, M. (2007) Tracking Tourists in the Digital Age, Annals of tourism Research, Vol. 34(1), pp. 141-159. 
Spek, S.C. van der (2008) Spatial Metro: Tracking Pedestrians in Historic City Centres. In Shaick, J., and Spek, S.C. van der (Eds) Urbanism on Track: Application of Tracking Technologies in Urbanism. Amsterdam: IOS Press. Delft University Press.

ten Hagen, K., Kramer, R., Modsching, M. \& Gretzelb, U. (2006) Capturing the Beaten

Paths: A Novel Method for Analysing Tourists' Spatial Behaviour at an Urban

Destination. In M. Hitz,, M. Sigala \& J. Murphy (Eds.) Information and Communication Technologies in Tourism, pp. 75-86. Vienna: Springer. 